\title{
Design and realization of an analog integrated circuit for maximum power point tracking of photovoltaic panels
}

\author{
Abdulrahman Alahdal $^{1}(\mathbb{D})$, Anis Ammous ${ }^{1,2}$ (D), and Kaiçar Ammous ${ }^{2, *}$ \\ ${ }^{1}$ Department of Electrical Engineering, CEIA-Umm Al Qura University, Makkah, Saudi Arabia \\ 2 Department of Electrical Engineering, National School of Engineers of Sfax, University of Sfax, Sfax, Tunisia
}

Received: 26 March 2021 / Received in final form: 26 October 2021 / Accepted: 10 January 2022

\begin{abstract}
The tracking of the maximum power point (MPP) of a photovoltaic (PV) solar panel is an important part of a PV generation chain. In order to track maximum power from the solar arrays, it is necessary to control the output impedance of the PV panel, so that the circuit can be operated at its Maximum Power Point (MPP), despite the unavoidable changes in the climate conditions such as temperature and Irradiance. A new MPPT analog technique to track the Maximum Power Point (MPP) of PV arrays is proposed. This new technique uses simple and classical functions of electronic circuits. An Off-Grid PV system was considered to apply and validate the proposed new technique. The entire circuit was implemented in circuit-oriented simulator Proteus-ISIS. We present the results associated with the design, the realization, and the experimentation of a PV system equipped with a new analog MPPT command. The obtained results have shown good efficiency of analog technique (more than $98.5 \%$ ). The second part of the paper consists of the description of the design and the realization of the novel analog MPPT integrated chip. The integrated circuit (IC) was designed and realized using HV CMOS technology $0.35-\mu \mathrm{m}$.
\end{abstract}

Keywords: Maximum power point tracking (MPPT) / analog technique / MPPT chip / integrated circuit (IC) / CMOS technology / Cadence

\section{Introduction}

People have gradually become aware of the importance of renewable energy. Global warming, climate change, increasing energy demand worldwide, and declining fossil fuel sources are key factors in the search for clean and sustainable energy. This new perspective reinforces the need for renewable energy sources such as solar, wind, and wave power. The sun is an accessible, free and nonpolluting source of energy that is considered a promising energy source because of its availability and benefits for local or grid-connected generations. The energy produced by $\mathrm{PV}$ systems depends on the climatic conditions related to sunshine and temperature and the connected load. Therefore, $\mathrm{PV}$ generators cannot be connected directly to the grid. Power converters are therefore at the heart of PV generation systems $[1,2]$.

Solar energy is one of the world's most attractive Renewable Energy Sources (RES). The different applications are lighting, Remote Site Electrification. Water Pumping and Control Charging Vehicle Batteries [3,4].

\footnotetext{
* e-mail: ammous.kaissar@gmail.com
}

The photovoltaic production is particularly non-linear and depends on many parameters (characteristics of the PV panel, sunlight, temperature, etc.). Therefore, the recovered energy is not necessarily always maximal. In this context, many researchers have focused to design electrical systems to always get the maximum energy: it is the principle of Maximum Power Point Tracker (MPPT). Few popular techniques, the Perturb and Observe (P\&O) [5,6], and the Incremental Conductance (Inc.Con.) [5,7] methods are the most effective. Both techniques have the advantages of good performance and easy implementation, but they also have drawbacks, as we will explain later. Other techniques based on different principles are Fractional Open Circuit Voltage or Short Circuit Current [8,9], Fuzzy Logic Control (FLC) [10,11], etc.

Various MPPT techniques have been well introduced, researched, and developed. The large number of techniques developed can make it difficult to determine the best method to adopt when implementing a PV system [11]. All these methods vary in terms of complexity, analog or digital implementation, tracking capability, speed of convergence, number of sensors required, and costeffectiveness. A good MPPT algorithm must produce a high efficiency at a squat cost since PV systems will have to be mass-produced. 
Alternatively, analog MPPT control strategies are gaining popularity due to their cost-effectiveness, simplicity, and low power requirements. A commonly used strategy when designing an analog MPPT is to use a comparator to detect changes in the load current. An analog controller using a charge current-based control strategy may easily be integrated into the power converter circuit. Moreover, digital MPPT is not well adapted to operation when environmental conditions change rapidly. Therefore, an analog method with optimized MPPT efficiency is essential to design many challenging circumstances with an unpredictable variation of irradiation from low to high, especially in space conditions [12].

In [13], for the track of the maximum power point of photovoltaic arrays, the fast dynamic method, known as ripple correlation control, is used. The principle of the RCC algorithm is based on the signal ripple automatically present in power converters. Ripple Correlation Control (RCC) is another improved MPPT technique that applies the hill-climbing concept. The higher efficiency reached by this technique is $97.2 \%$.

The authors present in [14] an analog version of the "P\&O-oriented" algorithm. The efficiency of the algorithm is greater than $99 \%$ but it uses more than thirteen discrete functions and two multiplier circuits.

An analog technique using two voltage approximation lines (VALs) that approach the location of the maximum power point (MPP) is proposed in [15]. Only simulation results are displayed, and more than four multiplier circuits are used. An efficiency of more than $98 \%$ was recorded. The authors of [16] utilize a wide range current multiplier, that follows the maximum power point (MPP) in the solar system. The slope detection circuit detects the sign of the slope $\mathrm{dP} / \mathrm{dV}$ at the operating point. The recorded MPPT efficiency is about $97.3 \%$.

The operating principle of the analog MPPT technique proposed in [17] is based on a truth table derived from the $\mathrm{P} \& \mathrm{O}$ algorithm. Several logic gates are required to implement the MPPT algorithm. Scaled VPV and PPV values are saved using capacitor-based storage cells. The number of discrete devices used is more than twenty-three. The efficiencies of the MPPT methods were assessed qualitatively based on simulations by considering the steady-state response of the system. The efficiency recorded is about $99.5 \%$. In literature, the various classical $\mathrm{P} \& \mathrm{O}$ or conductance incremental algorithms yield MPPT efficiency between $95 \%$ and $98 \%$. The new application of Artificial Neural Network (ANN) achieved 99.1\% [18,19].

In [20], the authors propose a fast and robust analog PV MPPT for the battery charging system using $d c-d c$ boost converter. Seven integrated circuits are used to perform the proposed technique. The MPPT technique efficiency was not evaluated.

The outline of this paper is following. After a brief introduction of this paper, the solar cell characteristics and PV module is described in Section 2. The operation principle of the new analog MPPT controller is described in Section 3. The design and realization of an integrated circuit (IC) in HV CMOS technology are described in Section 4. Finally, conclusions are summarized in Section 5 .

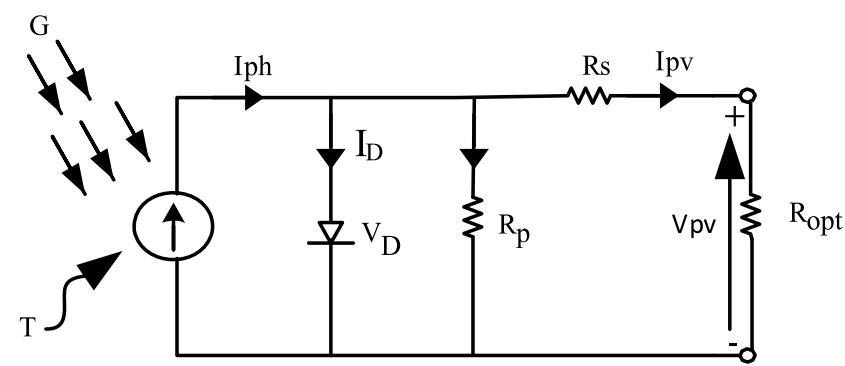

Fig. 1. Simplified equivalent circuit of solar PV cell.

\section{Solar cell characteristics and PV module}

The Photovoltaic effect is the process that generates direct current (DC) electrical power from sunlight $[17,21]$. In fact, a photovoltaic cell (name of the semiconductor element of a PV) is used for converting solar energy from direct sunlight to regulated electrical energy through the use of the photovoltaic effect [19]. Figure 1 illustrates a simplified equivalent circuit of a solar PV cell, which may be improved at different levels of accuracy and elaborations $[21,22]$. The terminal cell current $I_{\mathrm{pv}}$ is related to its terminal voltage by the following equation

$$
\mathrm{I}_{\mathrm{pv}}=\mathrm{I}_{\mathrm{PH}}-\mathrm{I}_{\mathrm{D}}-\left(\frac{\mathrm{V}_{\mathrm{D}}}{\mathrm{R}_{\mathrm{P}}}\right) .
$$

The photocurrent $I_{\mathrm{PH}}$ component, which characterizes the internally produced electrical current subsequent from the freed electrons within the PV. Its value is directly proportional to the quantity of sunlight incident on the surface of the cell semiconductor.

Two important factors that have to be taken into account are the irradiation $(G)$ and the temperature $(T)$.

The diode current $I_{\mathrm{D}}$ is given by the Shockley equation

$$
\mathrm{I}_{\mathrm{D}}=\mathrm{I}_{0}\left[\operatorname{Exp}\left(\frac{\mathrm{qV}}{\mathrm{nKT}}\right)-1\right]
$$

where $I_{0}, q, K$, and $T$ are respectively the PV cell reverse saturation current, the electron charge, the Boltzmann's constant, the cell operating temperature. $V$ is the voltage across the diode and $(n)$ is the diode ideality factor.

The PV cell has two boundary values: $V_{\text {oc }}$ being the cell's open-circuit voltage and $I_{\mathrm{sc}}$ being the cell's shortcircuit current at reference temperature: $25^{\circ} \mathrm{C}$ and reference irradiance: $1 \mathrm{~kW} / \mathrm{m}^{2}$.

The open-circuit voltage $V_{\mathrm{oc}}$ is given by the following equation:

$$
\mathrm{V}_{\mathrm{oc}}=\frac{\mathrm{nKT}}{q}\left[\ln \left(\frac{\mathrm{I}}{\mathrm{I}_{0}}\right)\right]
$$

The PV module may be characterized by the maximum power point (MPP) where the product of its voltage $V_{\mathrm{mpp}}$ and its current $I_{\mathrm{mpp}}$ are at their maximum value. The 


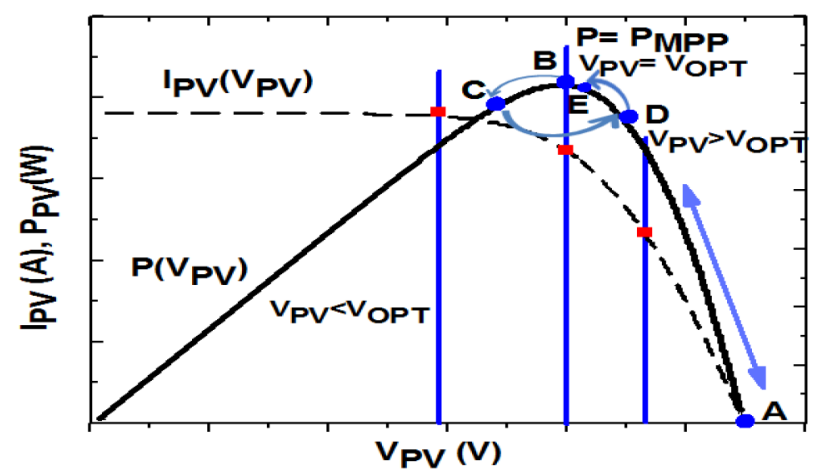

Fig. 2. $I_{\mathrm{pv}}-V_{\mathrm{pv}}, P_{\mathrm{pv}}-V_{\mathrm{pv}}$ characteristics of a solar cell showing MPP.

maximum power output $P_{\mathrm{mpp}}$ is derived by finding the local maxima of the product of PV output current and voltage [24].

$$
\frac{\mathrm{d}\left(\mathrm{V}_{\mathrm{PV}} \mathrm{I}_{\mathrm{PV}}\right)}{\mathrm{d} \mathrm{V}_{\mathrm{PV}}}=0
$$

and

$$
\mathrm{V}_{\mathrm{mp}}=\mathrm{V}_{\mathrm{oc}}-\frac{\mathrm{KT}}{\mathrm{q}}\left[\ln \left(\frac{\mathrm{V}_{\mathrm{mp}}}{\mathrm{nKT} / \mathrm{q}}+1\right)\right] .
$$

\section{Operation principle of the new analog MPPT controller}

The important factor in a photovoltaic generation is to operate at a high power efficiency system by ensuring that the system always operates at the peak power point regardless of load changes and atmospheric conditions (solar radiation and cell temperature). In other words, MPPT techniques consist of maintaining the $V_{\mathrm{MPP}}$ output voltage and $I_{\mathrm{MPP}}$ current at which a PV installation should operate to produce the maximum $P_{\mathrm{MPP}}$ output power under controlled irradiation and temperature conditions.

Figure 2 shows the current-voltage $\left(I_{\mathrm{pv}}-V_{\mathrm{pv}}\right)$ and power-voltage $\left(P_{\mathrm{pv}}-V_{\mathrm{pv}}\right)$ characteristics of a typical solar cell.

In this paper, we study the conception of a photovoltaic system equipped with a new analog Maximum Power Point Tracking (MPPT) technique. The proposed PV system consists of a DC switching chopper, a control system and a tracking system. The performance of the proposed analog technique was demonstrated using the Proteus-ISIS simulation tool [24].

\subsection{Typical PV system using proposed analog MPPT controller}

There are two main categories of PV systems: grid connection and stand-alone systems. In our case, we have chosen to develop the analog MPPT controller on a simple

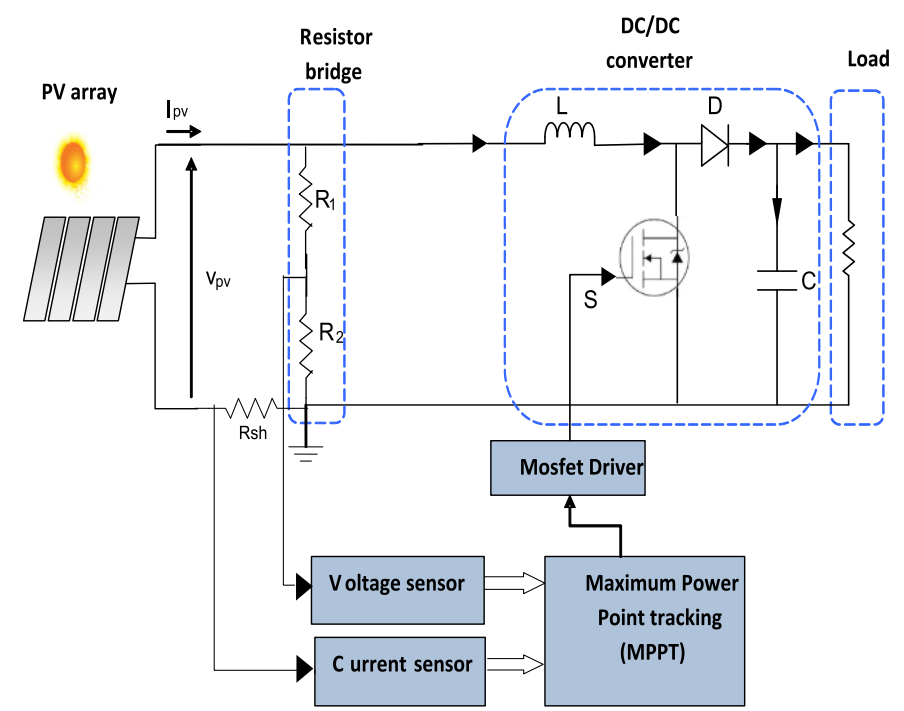

Fig. 3. Block diagram of a photovoltaic system adapted by DC/ DC converter and analog MPPT control.

and classical stand-alone PV system. Specific devices are needed to control, transfer, distribute, and store the energy produced by the photovoltaic panels. Figure 3 illustrates the block diagram of the adopted photovoltaic system.

The block diagram of Figure 3 includes:

- The PV arrays.

- Load that can be batteries or passive impedance.

- Power block formed by DC/DC boost power converter. In this case, the output voltage is higher than the one delivered by the PV array. The power converter involves one controlled switch (Mosfet or IGBT). The semiconductor device is controlled by a variable frequency and duty cycle $(\alpha)$ driving signal.

- Analog MPPT block. Allow the track of the maximal power point of the PV array, which depends on climate factors [24]. The power point of the PV array is then brought to its maximum. The principle of the analog controller consists of the variation of the, controlled switch, driving signal duty cyclic $(\alpha)$ in order to permanently maximize the power of the PV panel output.

The synoptic diagram of the photovoltaic technique is depicted in Figure 4. The analog MPPT circuit directly uses the voltage and current of the Photovoltaic array to look for the equivalent operating maximum power point.

- Shunt resistor $\left(R_{\mathrm{sh}}\right)$ that operates as a current sensor of the PV array output current.

- Voltage divider composed of two resistors " $R_{1}$ and $R_{2}$ ", in order to determine the PV generated supply voltage.

- Analog multiplier used to compute the instantaneous output power of the PV array.

- The reference power signal generated by $P_{\text {ref }}$ generator block. $P_{\text {ref }}$ signal has a maximum constant magnitude $(+15 \mathrm{~V})$, adjustable period $T_{\mathrm{s}}$, and constant $T_{\text {off }}$ (a few milliseconds). The slope rates values of the $P_{\text {ref }}$ waveform can be modified too (Fig. 6). The generator function is 


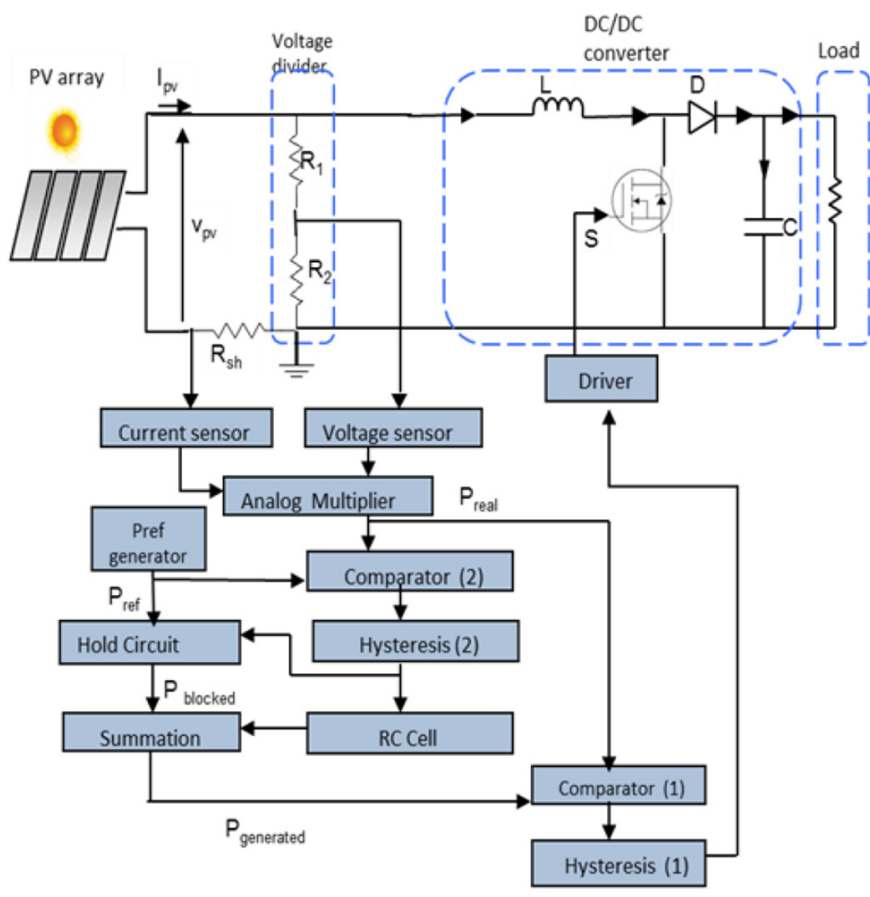

Fig. 4. The synoptic diagram of the whole photovoltaic technique.

based on the NE555 integrated circuit. This signal is used to generate $P_{\text {blocked }}$ signal and to be used for comparison with real power only during the rising phase of the signal until the maximum power, of the PV panels, is detected by the Hold Circuit.

- The real generated power $\left(P_{\text {real }}\right)$ is compared to the reference power signal $\left(P_{\text {ref }}\right)$ is done using a comparator (2).

- The detection of the MPP of PV arrays is performed using hysteresis (2) block. This block will control the Hold circuit, its output commute to $(+15 \mathrm{~V})$ when the comparator (2) output reaches $\varepsilon_{3}$ indicating the failover of the panels operating point to the left side of the $P(V)$ characteristic (point C in Fig. 2).

- A hold circuit that can block the value of the reference signal $\left(P_{\text {ref }}\right)$ and gives $P_{\text {blocked }}$ signal. The blocked value is slightly higher than the MPP of the panel's arrays. When $P_{\text {ref }}$ is blocked, the panel operating point is in (C).

- An RC cell that generates a pulse when the maximum power is reached (define the values of $\Delta \mathrm{V}_{2}$ and $\left(\Delta \mathrm{V}_{1}+\varepsilon_{3}\right)$ of the generated power shown in Fig. 6).

- The subtraction block produces $P_{\text {generated }}$ from blocked $P_{\text {ref }}$ and the RC circuit outputs. This block output allows to bring the panel operating point from (C) to (D) and to obtain, in the steady-state, the optimal value of the power detected by our technique (point E in Fig. 2).

- A comparator (1) that calculates the difference between the $P_{\text {real }}$ and the $P_{\text {generated }}$ for a real current regulation loop.

- The hysteresis (1) allows imposing the real power in a band around the optimal power ( $P_{\text {generated }}$ waveform) of

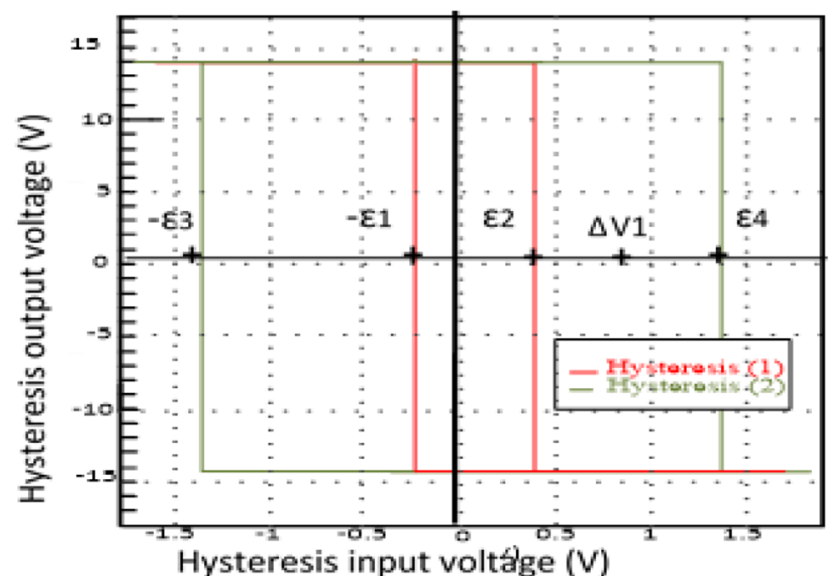

Fig. 5. The hysteresis (1) and the hysteresis (2) transfer functions.

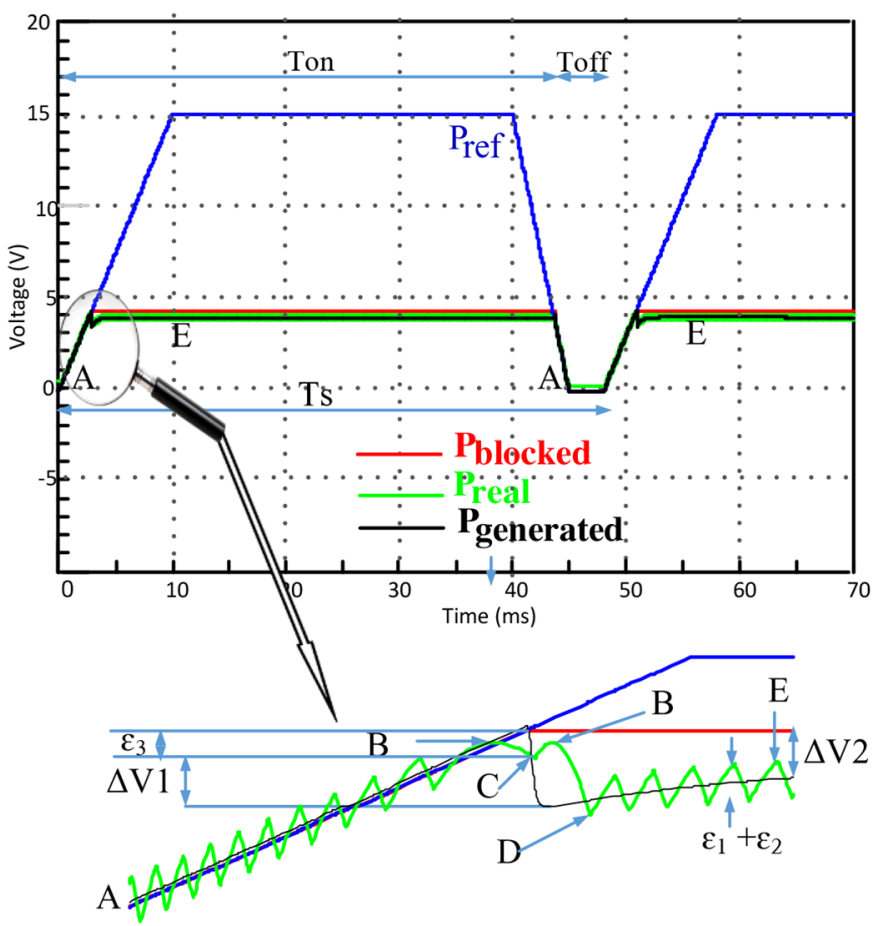

Fig. 6. Different Power waveforms evolutions and the corresponding PV panel operating point change.

the PV panel obtained by the proposed technique. If the error between the real power $P_{\text {real }}$ and the generated power $P_{\text {generated }}$ exceeds the upper or the lower limit of the hysteresis band, the real power $P_{\text {real }}$ is decreased or increased. The instantaneous control and the simplicity of the hysteresis technique make it more attractive than other control techniques. The output signal of the hysteresis block is injected to the Mosfet driver in order to control the DC-DC boost converter.

The transfer function of the hysteresis (2) and the hysteresis (1) blocks are shown in Figure 5. 
The transfer function of hysteresis 1 block is given by the following equations:

$$
\begin{gathered}
-\varepsilon_{1}=\frac{\left(R_{26} * V_{D D}\right)}{\left(R_{26}+R_{28}\right)} \\
\varepsilon_{2}=\frac{\left(R_{26} * V_{D D^{+}}\right)}{\left(R_{26}+R_{27}\right)} .
\end{gathered}
$$

The transfer function of the hysteresis 2 block is given by the following equations:

$$
\begin{gathered}
-\varepsilon_{3}=\frac{\left(R_{11} * V_{D D^{-}}\right)}{\left(R_{11}+R_{13}\right)} \\
\varepsilon_{4}=\frac{\left(R_{11} * V_{D D^{+}}\right)}{\left(R_{11}+R_{12}\right)} .
\end{gathered}
$$

\subsection{Proposed analog MPPT controller principle}

The majority of MPPT techniques attempt to vary PV current $I_{\mathrm{MPP}}$ in order to match the maximum power point, or to find the PV voltage that results in the maximum power point $V_{\mathrm{MPP}}$.

The proposed analog technique is based on the generation of a reference signal $\left(P_{\text {ref }}\right)$ that is swept along the $P(V)$ curve static characteristic. $P_{\text {ref }}$ generated signal is a square wave with controlled slope rates. It has a constant $T_{\text {off }}$ time, a variable period, and variable rising and falling slopes. The signal can vary between $0 / 15 \mathrm{~V}$ or $-15 /+15 \mathrm{~V}$ in order to increase precision (as it was implemented in the realized IC) and technique efficiency. $P_{\text {ref }}$ signal is to be followed by the PV panel's generated real power $\left(P_{\text {real }}\right)$ so such $P_{\text {real }}$ is lower than the maximum power $P_{\max }$ (between $\mathrm{A}$ and $\mathrm{B}$ of the power static characteristic $P(V)$ ) as shown in Figures 2 and 6 . Here the rough comparison is used by hysteresis 2 within tolerance $\varepsilon_{3}$.

$P_{\text {real }}$ that matches the maximum power point corresponds to a voltage well below $15 \mathrm{~V}$. When $P_{\text {real }}$ stops following $P_{\text {ref }}, P_{\text {blocked }}$ is equal to the value of last $P_{\text {ref }}+\varepsilon_{3}$. This is a rough estimate of MPP value, though a bit higher. The $P_{\text {blocked }}$ value is detected by the hysteresis2 (via the inverse circuit) and generated by the Hold circuit announcing the reach of the optimum power. Then, the RC block produces a negative pulse (corresponding to the decrease $\left(\Delta V 1+\varepsilon_{3}\right)$ in Fig. 6$)$ when added with the $P_{\text {blocked }}$ signal gives the signal $P_{\text {generated }}$. This power takes the role of $P_{\text {ref }}$ as long as the $P_{\text {real }}$ is within tolerance $\varepsilon_{2}$. The $P_{\text {real }}$ signal is brought to $P_{\text {generated }}$ signal by Hysteresis 1 . The target is for their difference to be within tolerance $\varepsilon_{1}$. This remains for the rest of $P_{\text {ref }}$ duty cycle, $T_{\text {on }}$. The whole process is repeated for each period of the signal $P_{\text {ref }}$.

Consequently, the panel operating point should be brought, from point $(\mathrm{C})$, to the right side of the $P(V)$ characteristic (point $\mathrm{D})$. A first-order pulse is declined from the blocked signal $P_{\text {blocked }}$ and $P_{\text {generated }}$ signal is obtained. Since the $P_{\text {real }}$ is to be brought to $P_{\text {generated }}$ by Hysteresis
(1), the panel operating point goes within its tolerance band (point D). During this transition, the operating point passes by the maximum power value (point $\mathrm{B}$ ).

The regulated real power pursues $P_{\text {generated }}$ until the operating point $(\mathrm{E})$ is slightly lower than the maximum value $P_{\max }$.

The hysteresis bands and first-order pulse magnitude are chosen so that the operating point $(E)$ is below the operating point $(B)$ on the right side of the $(P-V)$ characteristic.

At the end of the period $\left(T_{\text {on }}\right)$ and when the $P_{\text {ref }}$ signal decreases and becomes lower than actual power $P_{\text {real }}\left(\varepsilon_{4}\right.$ is exceeded), the hysteresis 2 reacts and cancels the hold block control signal. $P_{\text {generated }}$ and $P_{\text {blocked }}$ signals become equal to the falling reference signal. The actual power $P_{\text {real }}$ decreases too reaching the operating point (A). The initialization phase then restarts and will continue during the time $T_{\text {off }}$. The whole process is repeated with each $P_{\text {ref }}$ cycle. Figure 7 shows the proposed MPPT analog technique circuit and Table 1 was added for different system parameters and devices.

Table 1 shows the system parameters used for simulation.

We note that the $\mathrm{RC}$ cell circuit is a derivative $\mathrm{CR}$ function as shown in Figure 8.

The value of $\Delta V_{2}$ is fixed by the $\mathrm{RC}$ circuit and it is chosen given by the following condition.

$$
\Delta V_{2}-\varepsilon_{2}>\varepsilon_{3} .
$$

This condition is necessary to be sure that the operating point of the PV panels is kept in the right side of the maximum point of the $P(V)$ characteristic.

\subsubsection{Simulation results}

The simulation results of the implemented circuits have been made in the program Proteus Isis 7.7 [24]. The change in the level of irradiance effect is presented in order to show the robustness of the proposed technique. The effect of different levels of irradiation is presented in Figure 9. It is clear that real power converges, during the steady-state, to a value $(E)$ slightly lower than the array's maximum power $(B)$. The difference between the generated real power and the optimal panel power contributes to the performance assessment of the proposed analog technique [25-26].

The efficiency of the proposed MPPT technique has been calculated for different $T_{\text {on }}$ values. Figure 10 illustrates how this efficiency changes as a function of radiation intensity for two $T_{\text {on }}$ values $\left(T_{\text {off }}=4 \mathrm{~ms}\right.$ as an example). The efficiency was calculated by the following equation.

$$
\eta=\frac{\int_{0}^{\mathrm{Ts}} \mathrm{P}_{\mathrm{real}}}{\int_{0}^{\mathrm{Ts}} \mathrm{MPP}} .
$$

We notice that the maximum efficiency reaches $99.3 \%$ at $1000 \mathrm{~W} / \mathrm{m}^{2}$. In literature, the various classical $\mathrm{P} \& \mathrm{O}$ or conductance incremental algorithms yield MPPT efficiency between $95 \%$ and $98 \%$. 


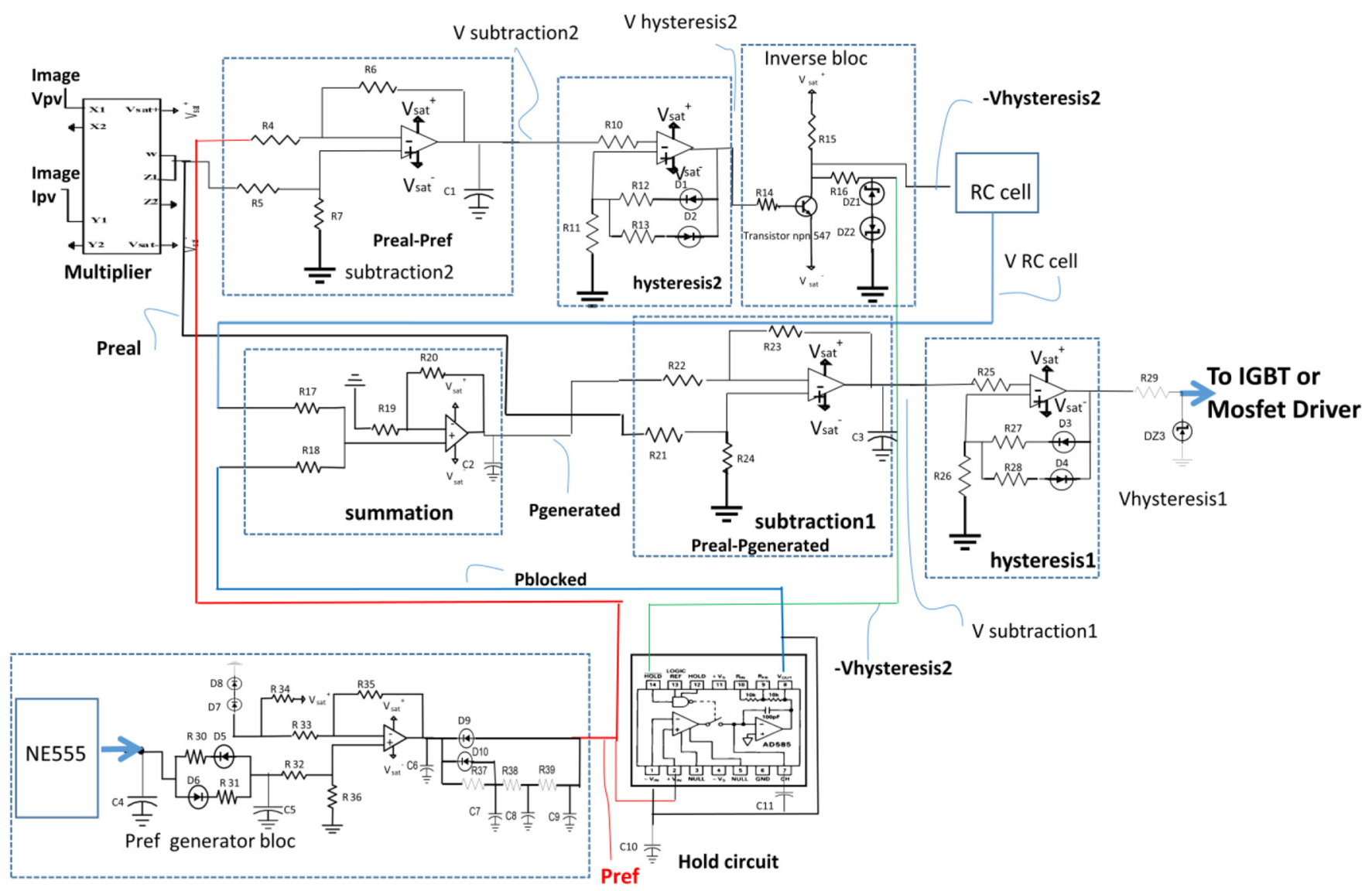

panel operating point change

Fig. 7. The proposed analog MPPT technique circuit.

Table 1. The system parameters used for simulation.

\begin{tabular}{ll}
\hline System block & Parameters and devices \\
\hline Hysteresis 1 & $R_{25}=100 \mathrm{ohm}, R_{28}=20 \mathrm{k}, R_{27}=30 \mathrm{k}, R_{26}=510 \mathrm{ohm}, 2$ Diodes $1 \mathrm{n} 4148$, Diode \\
& Zener DZ3 $=12 \mathrm{v}, R_{29}=3 \mathrm{k}$ \\
Hysteresis 2 & $R_{10}=100 \mathrm{ohm}, R_{11}=3.5 \mathrm{k}, R_{12}=20 \mathrm{k}, R_{13}=22 \mathrm{k}, 2$ Diodes $1 \mathrm{n} 4148$ \\
Summation & $R_{17}=20 \mathrm{k}, R_{18}=20 \mathrm{k}, R_{19}=20 \mathrm{k}, R_{20}=20 \mathrm{k}, \mathrm{C}=2.2 \mathrm{nF}$ \\
Comparator 1 & $R_{21}=12.5 \mathrm{k}, R_{22}=12.5 \mathrm{k}, R_{23}=51 \mathrm{k}, R_{24}=51 \mathrm{k}, \mathrm{C}=2.2 \mathrm{nF}$ \\
Comparator 2 & $R_{4}=12.5 \mathrm{k}, R_{5}=12.5 \mathrm{k}, R_{6}=51 \mathrm{k}, R_{7}=51 \mathrm{k}, \mathrm{C}=2.2 \mathrm{nF}$ \\
Inverting circuit & $R_{14}=150 \mathrm{k}, R_{15}=1.5 \mathrm{k}, R_{16}=1 \mathrm{k}, 2$ Diode Zener $=12 \mathrm{v}$, Transistor npn 547 \\
$P_{\text {ref }}$ generator & $R_{30}=1 \mathrm{k}, R_{34}=100 \mathrm{k}, R_{31}=6 \mathrm{k}, R_{32}=510$ ohm, $R_{33}=20 \mathrm{k}, R_{34}=40 \mathrm{k}, R_{35}=20 \mathrm{k}$, \\
Holder D585 & $R_{36}=40 \mathrm{k}, R_{37}=R_{38}=R_{39}=60 \mathrm{k}, 6$ Diode $1 \mathrm{n} 4148,6$ Capacitors $=100 \mathrm{nF}$, NE555 \\
Multiplier & $C_{10}=66 \mathrm{nF}, C_{11}=27 \mathrm{pF}, \mathrm{AD} 585$ \\
\hline & $\mathrm{MPY} 634$ \\
\hline
\end{tabular}

\subsubsection{Experimental validation of the proposed MPPT technique}

To verify the accuracy of the proposed analog MPPT method, a circuit prototype is implemented from which simulations and experiments are carried out accordingly.
A laboratory arrangement has been implemented in order to verify the performance of the maximum power point tracker proposed in this work. For this purpose, the Boost converter was realized, the used semiconductor devices are the STGW30V60F N-channel IGBT and the MUR1560 Diode. The DC-DC boost converter allows the connection 


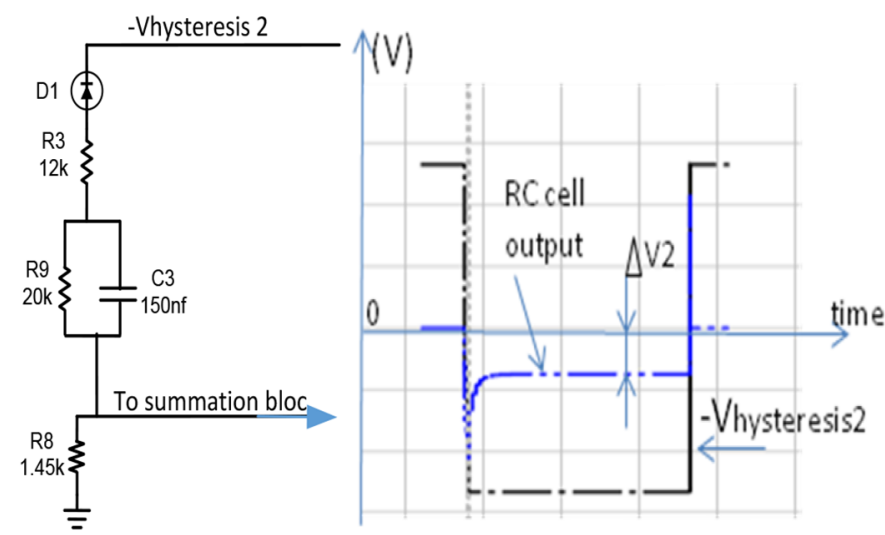

Fig. 8. The RC cell circuit and its input/output voltage waveforms.

and the power transfer of the generated power by the panels to the output load (DC bus). In our case, the used load is a power resistor.

Figure 11 shows the photo of the realized MPPT control circuit that has generated the signal to control the IGBT component of the boost converter and the photo of the realized Boost power circuit used to connect $\mathrm{PV}$ panels to the DC load [26,27]. Table 2 gives the electrical parameters of the elementary used PV Panel. In order to detect, in real-time, the real maximum power generated by the PV panels, during the tracking process, the value of the point (B) shown in Figure 6 was registered. This allows evaluating the efficiency of the proposed technique given by equation (10).

Figure 12 shows the static characteristics, of the used three series panels, obtained by experiments.

We have experimented with the global PV system equipped with the analog MPPT circuit. Figure 13 shows the evolutions of the $P_{\text {real }}$ and the $P_{\text {generated }}$ power signals. It is clear that $P_{\text {real }}$ is brought to $P_{\text {generated }}$ signal whose magnitude is considered equal to the optimal power of the $\mathrm{PV}$ panel at a given irradiation level. The signal $V_{\text {hysteresis2 }}$ triggers the blocking of the $P_{\text {ref }}$ signal to the optimal value of the panel power.

A zoom was done on the $P_{\text {real }}$ waveform in order to show its transient behaviors just when the optimum power of the panel has been reached.

We notice that in all experimental waveforms, the $T_{\text {on }}$ duration value of the $P_{\text {ref }}$ signal was chosen low (around $50 \mathrm{~ms}$ ) in order to be able to show complete period waveforms in the oscilloscope.

The value of the MPP detected by the proposed technique is lower than the real value $(\mathrm{B})$, the difference between them is less than $\Delta V_{2}$ as shown in Figure 6 .

In practice, the duty cycle of $P_{\text {ref }}$ signal is close to 1 since $T_{\text {off }}<T_{\text {on }}$. If the magnitude of the point $(\mathrm{B})$ reaches $12 \mathrm{~V}$ for example, and if $\Delta V_{2}$ is around $0.4 \mathrm{~V}$. when the $P_{\text {ref }}$ is defined between $-15 \mathrm{~V}$ and $15 \mathrm{~V}$, the efficiency registered in this case is $>0.985$.

Table 3 lists a comparison between the number of main electronic functions obtained by some techniques proposed in the literature and the technique proposed here.
The proposed technique offers a lower number of electronic functions with more accurate results. In fact, the used hysteresis technique, to track the power reference, allows an excellent dynamic response of the instantaneous power.

\section{Design and realization of an integrated circuit (IC) in HV CMOS technology}

The main task here is to design and implement an integrated circuit (IC) in CMOS technology to track the PV panel MPP. The MPPT controller can be made small enough to be integrated into the junction box, which is practical and cost-effective for MPPT topology [32]. For the design, two main steps are necessary. First, the frontend step, which consists of the validation of the design by the Cadence simulation tool [33]. These steps are crucial since they determine the performance capability of the design. The second phase is the back-end step, which consists of the circuit layout generation. If the obtained results are satisfactory, in this case the circuit is ready for fabrication [34].

\subsection{Operational amplifier (AOP) circuit design}

In analog design, an operational amplifier is the most important, and most widely used fundamental circuit, which is usually a part of other analog and mixed-signal circuits. Operational amplifiers, more commonly known as Op-amps, are among the most widely used building blocks in analog. The circuit uses a dual-polarity power supply ( $V_{\mathrm{dd}}$ and $V_{\mathrm{ss}}$ ). CMOS technology is becoming more dominant than BJT technology because it offers several advantages such as smaller size, less power consumption, and flexibility of combining with digital circuits.

OPAMP is a fundamental building block in analog integrated circuit design. The operational amplifier (Op-Amp) is a high gain differential amplifier that can perform a wide variety of analog signal processing tasks such as integrator, differentiator, summation, etc... with only a handful of external components [35,36].

Figure 14 shows the designed full custom - two-stage CMOS operational amplifier topology and its symbol. The designed AOP's operate at a High voltage $\pm 15 \mathrm{~V}$ power supply using AMS H35 technology.

Figure 15 presents the simulated gain and phase of the designed AOP. The simulation result shows a voltage gain of $95.56 \mathrm{~dB}$ and a phase margin of $49.5^{\circ}$.

\subsection{Realization of the analog MPPT control circuit}

The new analog MPPT integrated circuit is expected to have better efficiency than numerical MPPT classical techniques. The MPPT module, as the core module of the chip, encompass Analog Multiplier, comparator (1,2), Hold Circuit, Subtracter, RC CELL, Hysteresis $(1,2)$, and other blocks. Figure 16 shows the internal functions blocks of the proposed analog MPPT Controller IC. We notice that additional output pins are provided in the new IC in order to test the different integrated functions separately. 


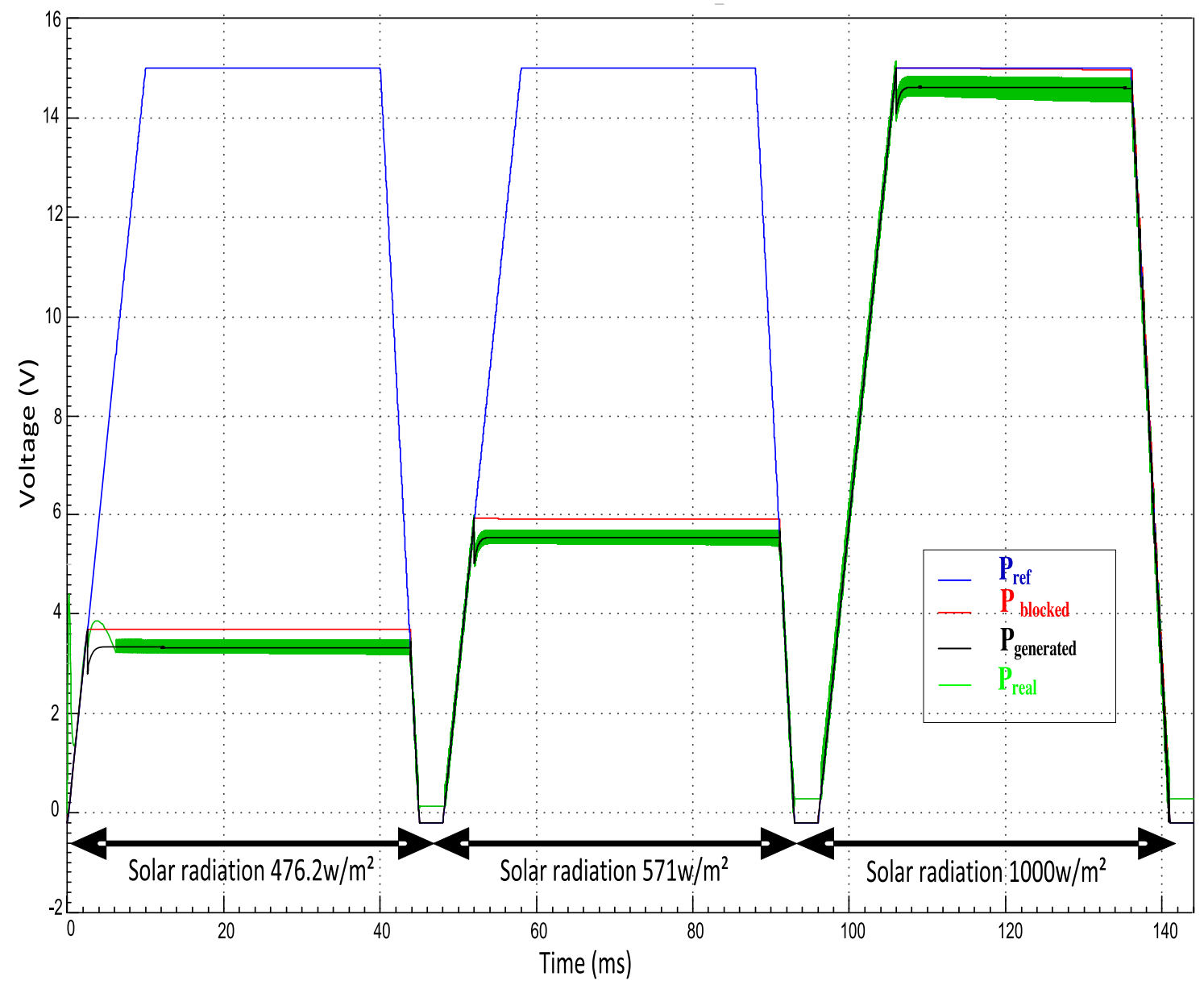

Fig. 9. Tracked maximum power under variable solar radiation.

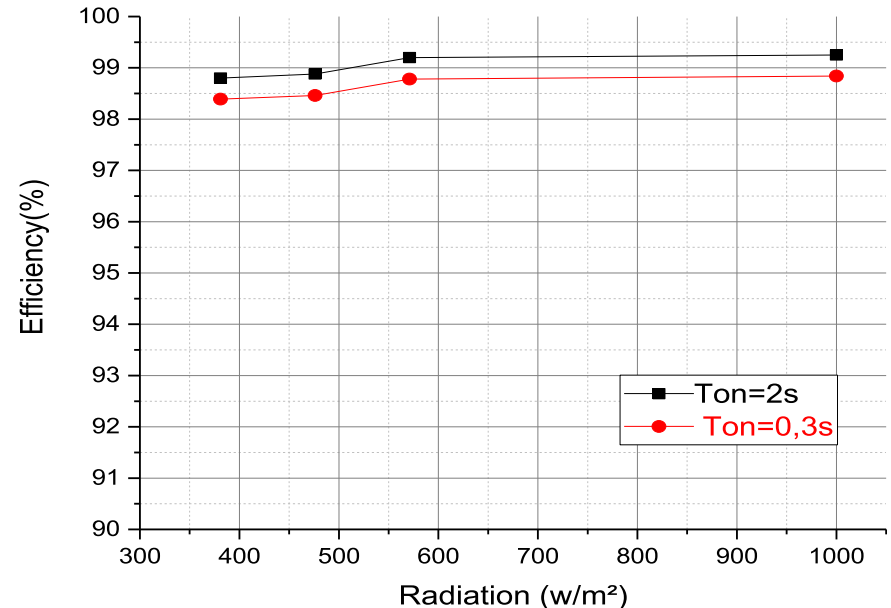

Fig. 10. Proposed MPPT technique efficiency as a function of irradiation when the reference power signal $\left(P_{\text {ref }}\right)$ varies between $-15 \mathrm{~V}$ and $15 \mathrm{~V}$ as it was integrated into the new IC.
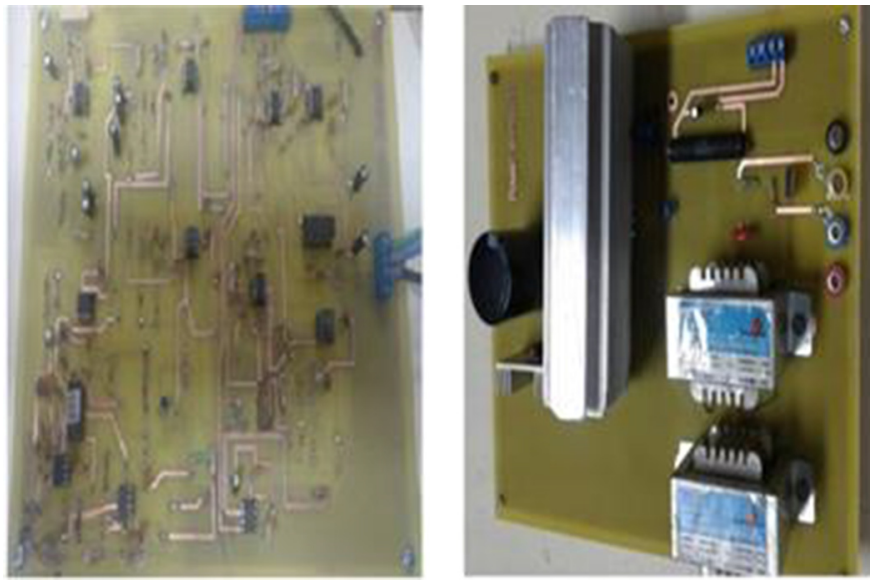

Fig. 11. Photo of the realized PMMT control circuit and the Boost power circuit. 
Table 2. Typical electrical characteristics of a PV module JASOLAR (at $25^{\circ} \mathrm{C}$ and $1000 \mathrm{~W} / \mathrm{m}^{2}$ ).

Characteristics Specification

Maximum power rating

Open circuit voltage $\left(V_{\text {oc }}\right)$ $265 \mathrm{~W}$

Short circuit current $\left(I_{\mathrm{sc}}\right)$

$38.38 \mathrm{~V}$

Maximum power voltage $\left(V_{\mathrm{mp}}\right)$

$8.8 \mathrm{~A}$

Maximum power current $\left(I_{\mathrm{mp}}\right)$

$31.24 \mathrm{~V}$

$8.48 \mathrm{~A}$

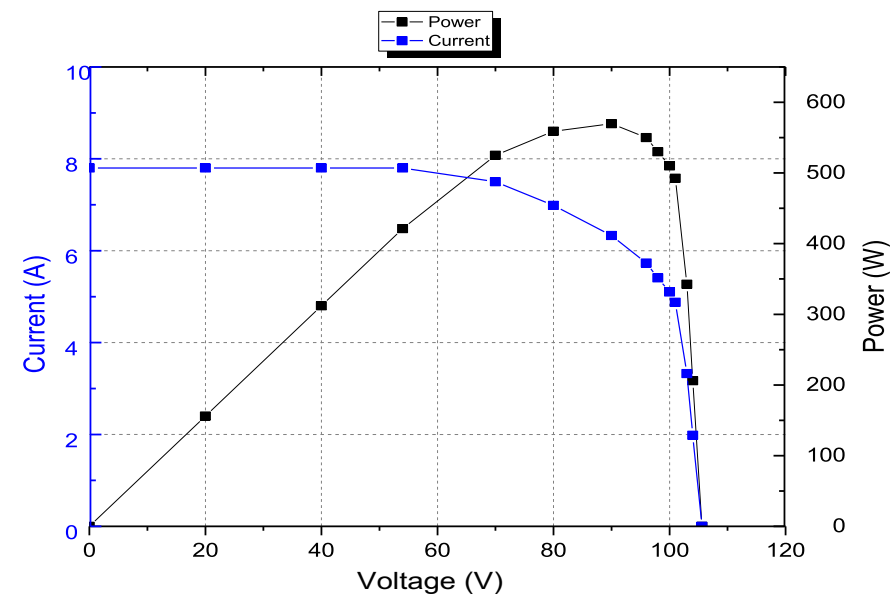

Fig. 12. Experimental evolution of the $I(V)$ and $P(V)$ panel characteristics.

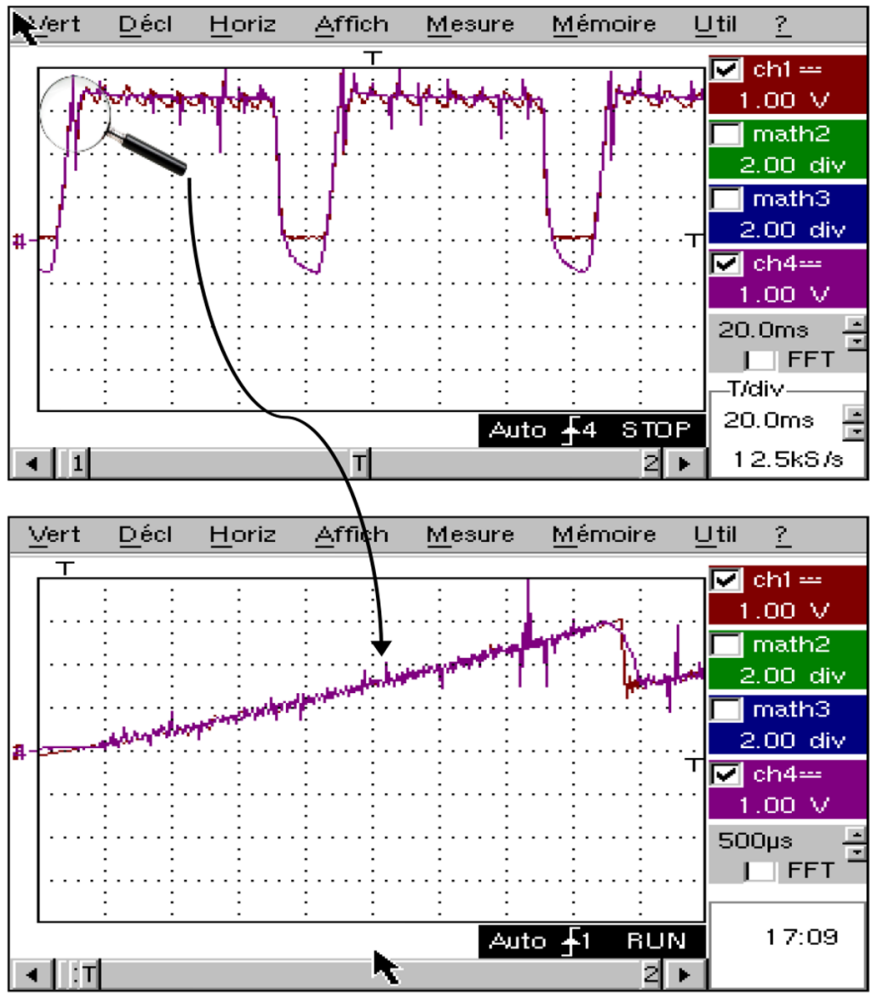

Fig. 13. Steady-state operation of analog MPPT controller (ch1) Preal (1V/division) (ch4) Pgenerated (1V/division). 
Table 3. Comparison between number of electronic functions used in our technique and in techniques published in literature.

\begin{tabular}{|c|c|c|}
\hline$\underline{\text { References }}$ & Principal functions & Function number \\
\hline \multirow[t]{6}{*}[25-27]{} & Analog Multiplier & 1 \\
\hline & Comparators & 2 \\
\hline & Pref generator & 1 \\
\hline & A sample \& Hold (S\&H) circuit & 1 \\
\hline & Subtractor & 1 \\
\hline & Hysterisis & 2 \\
\hline \multirow[t]{9}{*}{ [16] } & Reference voltage circuit & 1 \\
\hline & PWM circuit & 1 \\
\hline & Analog multipliers AD633J & 2 \\
\hline & Differentiators & 2 \\
\hline & Comparators & 3 \\
\hline & Integrator & 1 \\
\hline & Limit & 1 \\
\hline & Low pass RC filter & 1 \\
\hline & low offset voltage & 2 \\
\hline \multirow[t]{6}{*}[28]{} & Sample/hold circuit & 1 \\
\hline & Multipliers & 2 \\
\hline & Voltage-to-current converter & 1 \\
\hline & Subractors & 2 \\
\hline & Current comparator & 1 \\
\hline & Wide Range Squaring Circuits & 2 \\
\hline \multirow[t]{10}{*}[29]{} & Current sensor gain for I_PV & 1 \\
\hline & Voltage sensor gain for $\mathrm{V}_{-} \mathrm{PV}$ & 1 \\
\hline & Low pass filter (LFP) & 2 \\
\hline & Analog multiplier & 1 \\
\hline & A sample \& hold (S\&H) block & 1 \\
\hline & Voltage-to-current converter & 1 \\
\hline & PWM comparator & 1 \\
\hline & Logic circuit (SR flip-flop And logic gates & 1 \\
\hline & Flip-flops, & 1 \\
\hline & Current mirror conversion gain & 1 \\
\hline \multirow[t]{7}{*}[30]{} & Multiplier & 1 \\
\hline & Integrators & 2 \\
\hline & Comparators & 2 \\
\hline & A Flip-Flop & 1 \\
\hline & Integrator (Ro, Co) & 1 \\
\hline & Triangular Generator & 1 \\
\hline & CDCS Circuit & 1 \\
\hline \multirow[t]{7}{*}[31]{} & Analog multiplier & 1 \\
\hline & Bias circuit & 1 \\
\hline & MPPT decision-made circuit & 1 \\
\hline & Digital control blocks & 2 \\
\hline & Reference voltage circuit (storage circuit), & 1 \\
\hline & PWM driver circuit & 1 \\
\hline & Clock generating block includes (oscillator, clock divider, clock delay circuit) & 1 \\
\hline
\end{tabular}




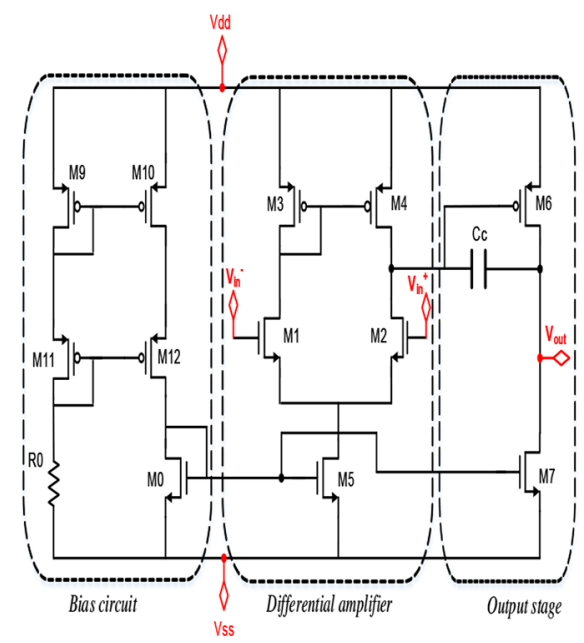

(a)

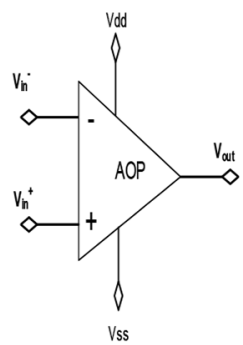

(b)

Fig. 14. (a) Structure of the high voltage amplifier and (b) its symbol.

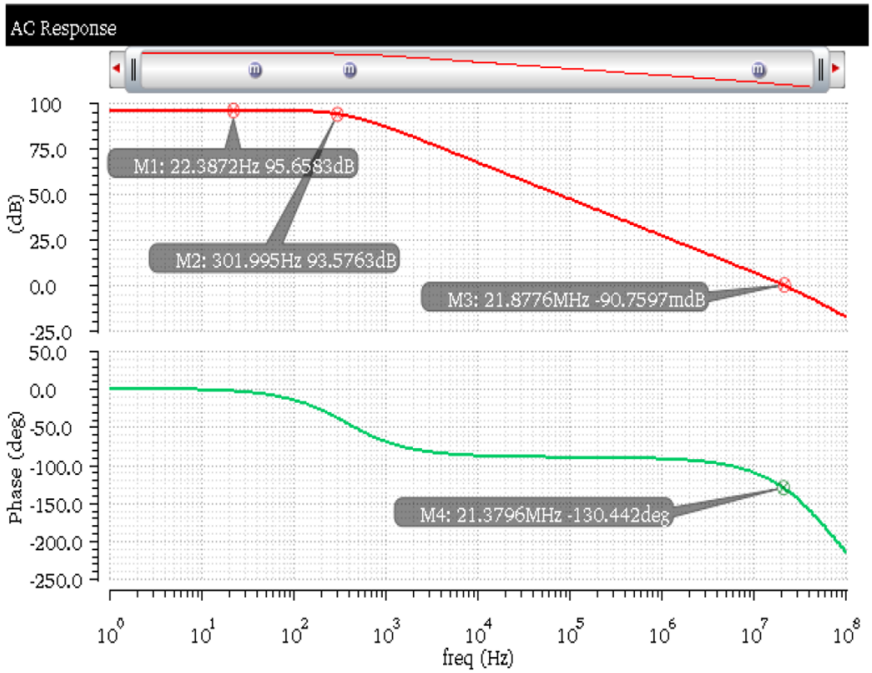

Fig. 15. The output waveform of Open-loop gain.

The circuit layout is depicted in Figure 17.

Figure 18 presents the integrated circuit pins. The realized sample package (40-pin ceramic) of the MPPT IC is shown in Figure 19a. Typically a cover keeps the chip from being exposed to light or accidental damage. A zoom on the chip after realization is shown in Figure 19b.

Figure 20 shows the whole photovoltaic circuit associated with the new MPPT IC.

Experimental investigations were performed to validate the proposed new analog technique on a boost converter in a nanogrid PV application. The experimental results

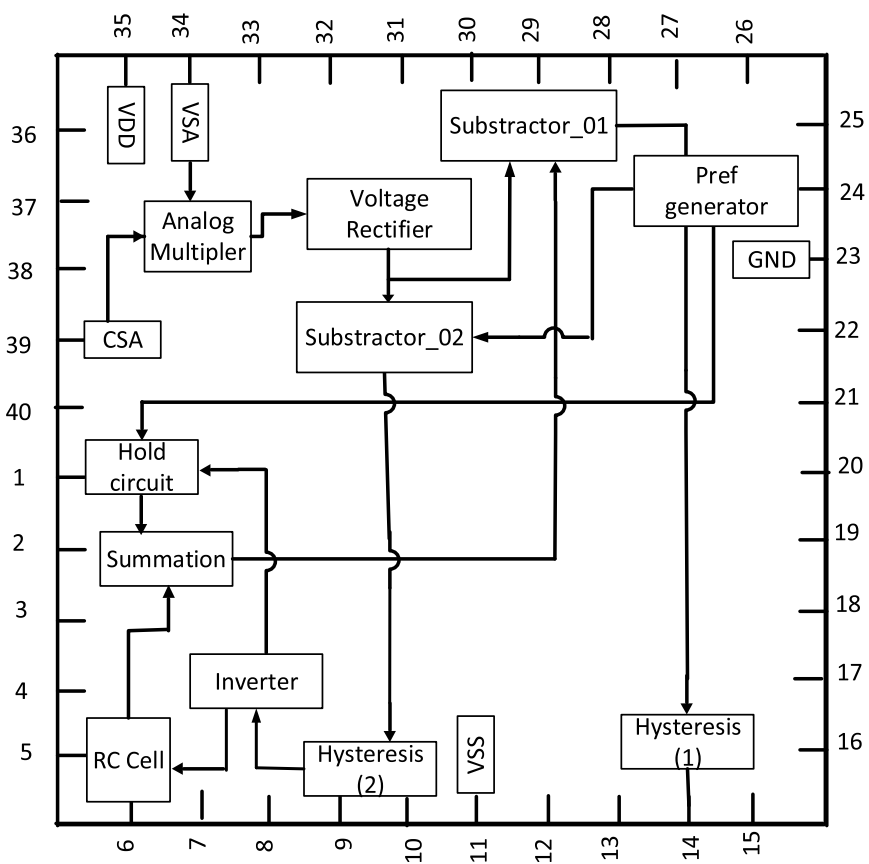

Fig. 16. Internal of the proposed analog Mppt controller IC.

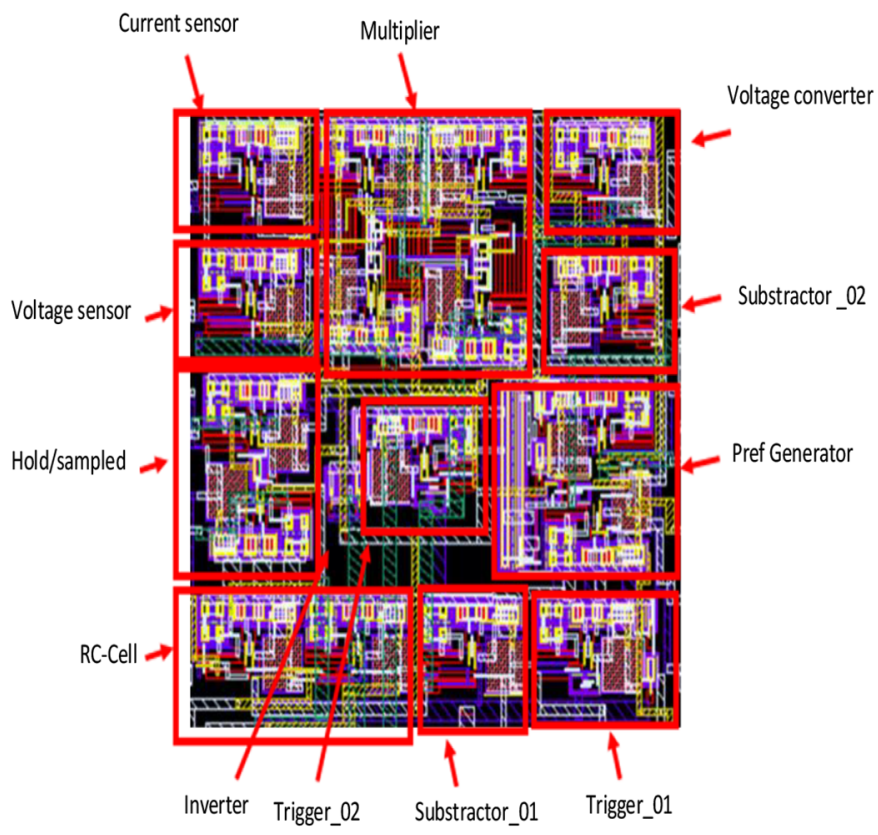

Fig. 17. Integrated circuit layout.

confirmed the effectiveness of the implementation proposed in this work. The proposed idea showed its accuracy to detect and follow the optimal generated power by the PV arrays.

The PCB card used to test the MPPT analog IC and the registered output power are shown in Figure 21. 


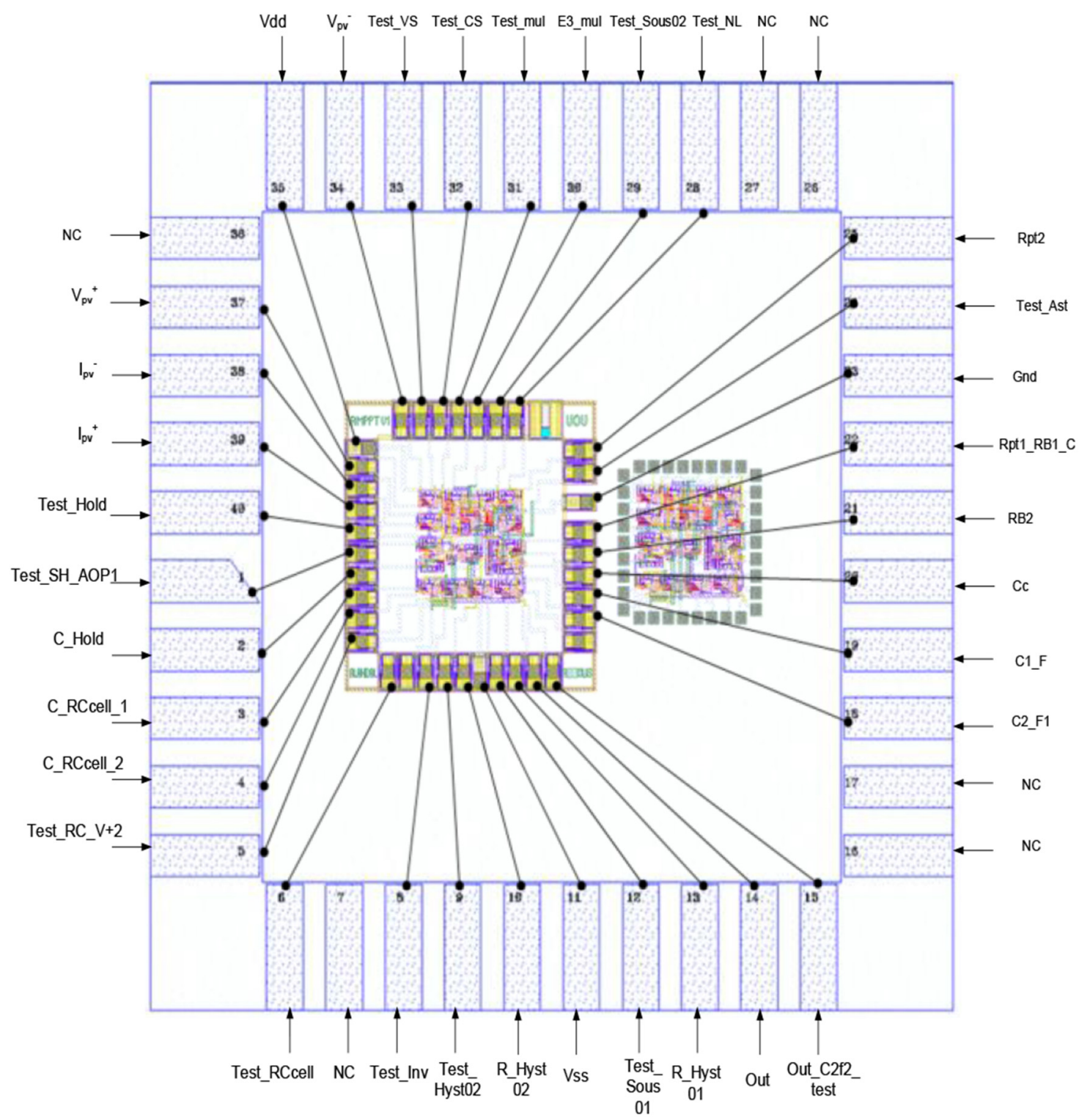

Fig. 18. The circuit pins.

Figure 22 shows the effect of the irradiance variation (due to cloud) on the real power.

\section{Conclusion}

A new analog technique to track the maximum power point (MPP) PV panel operation is proposed in this paper. The proposed MPPT control strategy has the ability of fast track the MPP for PV systems offering high efficiency. Through simulation by Proteus ISIS, the accuracy and feasibility of the proposed method were validated using a power boost convertor.
The proposed solution was validated by experimental tests carried out on a prototype of the power converter and the analog circuit-based control platform. Experimental results are in agreement with the expected targets. The proposed MPPT idea showed its accuracy to detect the optimal generated power by the PV panels. It offers a lower number of electronic functions with more accurate results, the used hysteresis technique, allows an excellent dynamic response of the instantaneous power.

The second part of the paper has been devoted to the design of the different sub-circuits of the IC in the Cadence design tool. The design of the whole integrated circuit was performed using the HV CMOS technology $0.35-\mu \mathrm{m}$. 


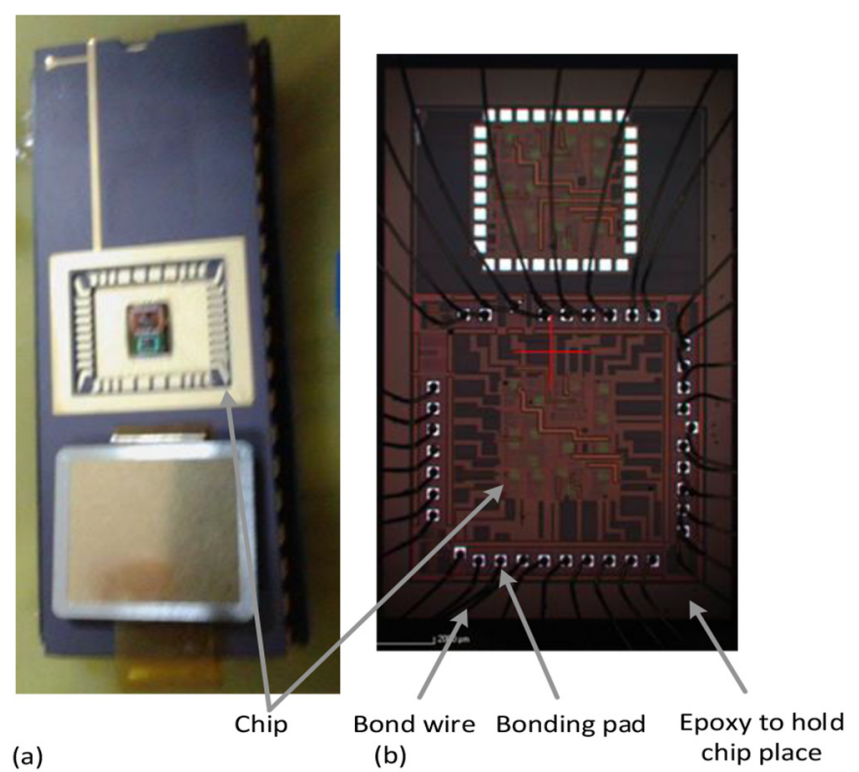

Fig. 19. How a chip is packaged (a) and (b) a closer view.

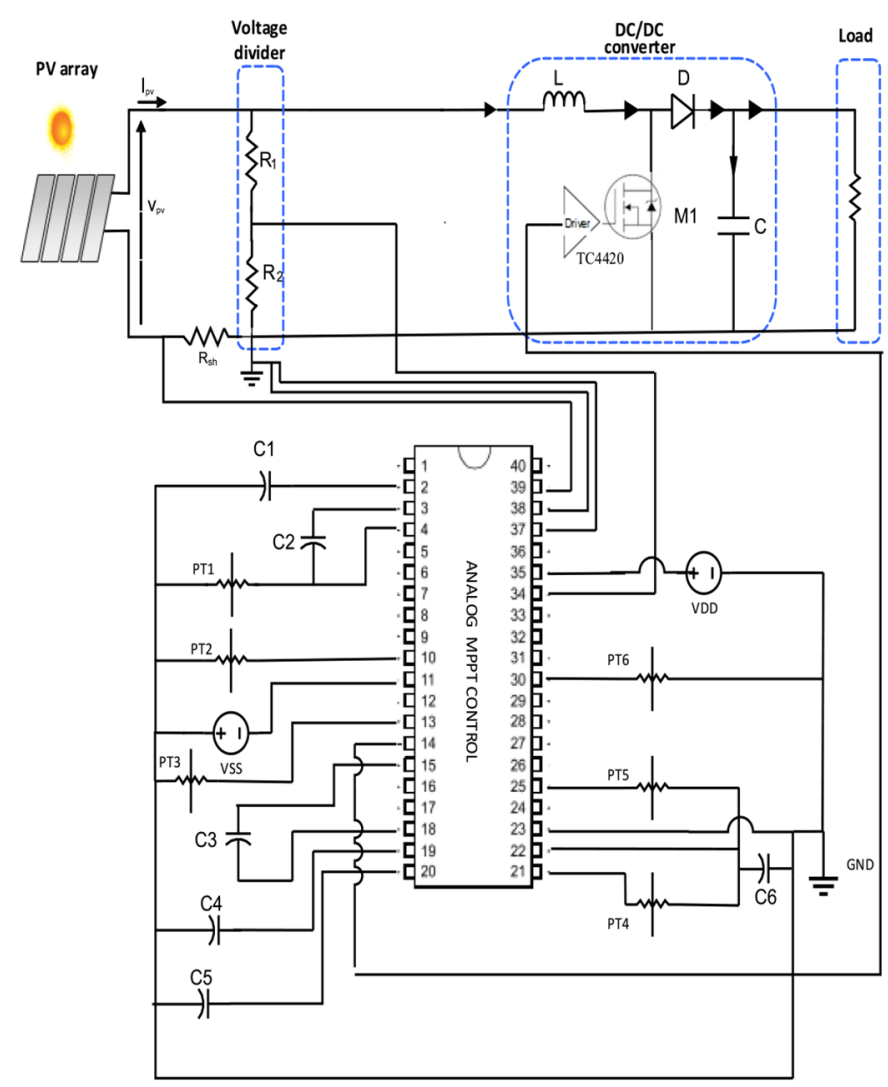

Fig. 20. Schematic of the proposed circuit with the designed IC and passive components.

The choice of the HV CMOS process and a few external circuit components of the system bring an important reduction of the system costs, thus making it cost-effective for analog MPPT control topology.

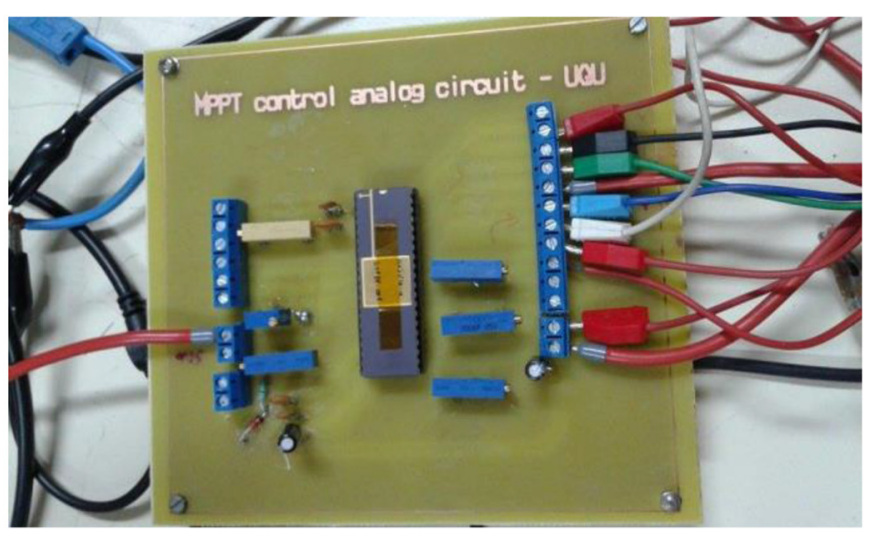

(a)

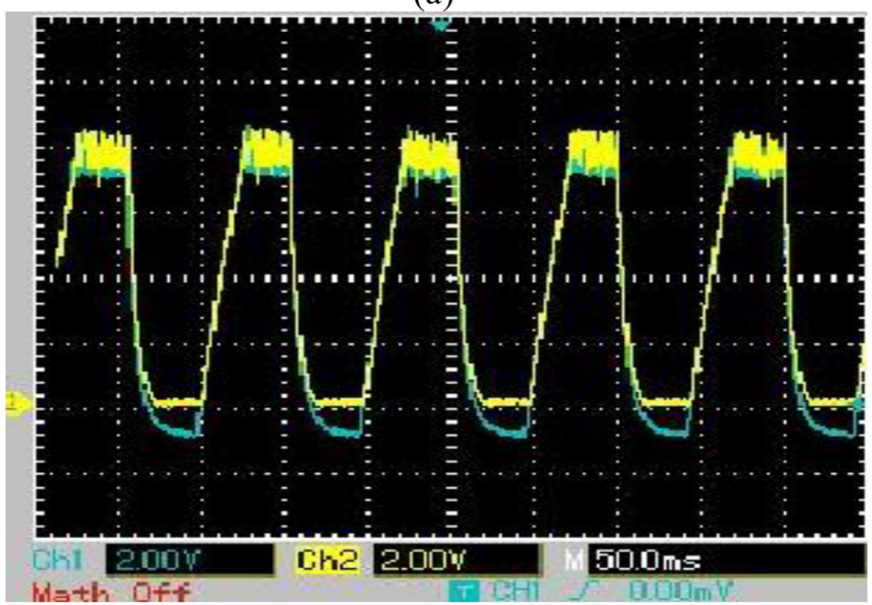

(b)

Fig. 21. (a) The PCB card used to test the MPPT analog integrated circuit. (b) Output and $P_{\text {ref }}$ powers.

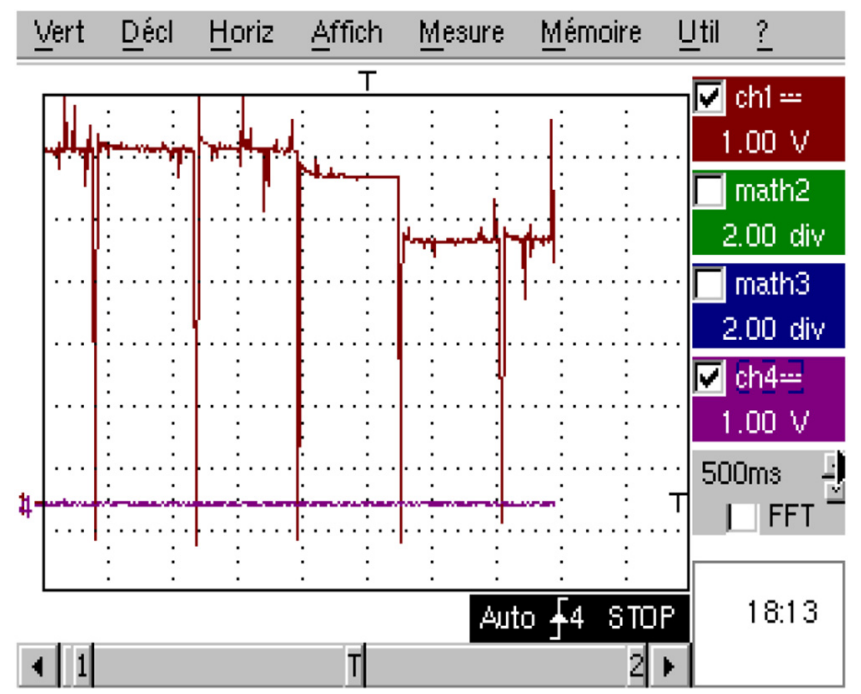

Fig. 22. $P_{\text {real }}(\mathrm{ch} 1)$ waveform due to irradiance variation. 
The authors extend their appreciation to the Deputyship for Research \& Innovation, Ministry of Education in Saudi Arabia for funding this research work through project number 1212 .

\section{Author contribution statement}

Anis Ammous proposed the idea and contributed to the design and the realization. Abdulrahman Alahdal contributed to the simulation and writing the manuscript. Kaiçar Ammous contributed to the realization and writing the manuscript.

\section{References}

1. T. Mrabti, M. ElOuariachi, R. Malek, Ka. Kassmi, B. Tidhaf, F. Bagui, F. Olivié, K. Kassmi, Design, realization and optimization of a photovoltaic system equipped with analog maximum power point tracking (MPPT) command and detection circuit of the dysfunction and convergence the system (CDCS), Int. J. Phys. Sci. 6, 7865 (2011)

2. Y.-H. Liu, Z.-Z. Yang, S.-C. Wang, J.-W. Huang, A novel analog MPPT technique for low power photovoltaic systems, in Proceedings of the 2011 IEEE Region 10 Conference: Trends and Development in Converging Technology Towards 2020, TENCON 2011 (2011), pp. 833-837 (2011)

3. T.D. Roy, Simulation and Analysis of Photovoltaic StandAlone Systems, Thesis, India, 2013

4. F. Kano, Y. Kasai, H. Kimura, H. Funato, MPPT circuit with analog control suitable for solar cars, Electr. Eng. Jpn. 213, $43(2020)$

5 . K. Ishaque et al., The performance of perturb and observe and incremental conductance maximum power point tracking method under dynamic weather conditions, Appl. Energy 119, 228 (2014)

6. S.E. Babaa, M. Armstrong, V. Pickert, Overview of Maximum Power Point Tracking Control Methods for PV Systems, Journal of Power and Energy Engineering 2, 59 (2014)

7. R. Ika Putri et al., Maximum power point tracking for photovoltaic using incremental conductance method, Energy Procedia 68, 22 (2015)

8. S. Sarangi, Maximum power point tracking (MPPT) - a review on innovative algorithms, IJAREEIE 04, 615 (2015)

9. S. Saravanan, N. Ramesh Babu, Maximum power point tracking algorithms for photovoltaic system - a review, Renew. Sustain. Energy Rev. 57, 192 (2016)

10. A.R. Reisi, M.H. Moradi, S. Jamasb, Classification and comparison of maximum power point tracking techniques for photovoltaic system:a review, Renew. Sustain. Energy Rev. 19, 433 (2013)

11. B. Subudhi, R. Pradhan, A comparative study on maximum power point tracking techniques for photovoltaic power systems, IEEE Trans. Sustain. Energy 4, 89 (2013)

12. M.L. Hoang, Photovoltaic system optimization by new maximum power point tracking (MPPT) models based on analog components under harsh condition, Energy Harvest. Syst. 6, 57 (2019)

13. T. Esram, J.W. Kimball, P.T. Krein, P.L. Chapman, P. Midya, Dynamic maximum power point tracking of photovoltaic arrays using ripple correlation control, IEEE Trans. Power Electr. 21, 1282 (2006)
14. M. Azab, A new maximum power point tracking for photovoltaic systems, Int. J. Electr. Electr. Eng. 3, 702 (2009)

15. G. El-Saady, A. El-NobiIbrahim, M. EL-Hendawi, Simulated annealing modeling and analog MPPT simulation for standalone photovoltaic arrays, Int. J. Electr. Electr. Eng. 4, $353(2013)$

16. J.M. Enrique, J.M. Andujar, M.A. Bohoérquez, A reliable, fast and low cost maximum power point tracker for photovoltaic applications, Solar Energy 84, 79 (2010)

17. R.P. Roll, Development of new parameter extraction schemes and maximum power point controllers for photovoltaic power systems, Thesis, 2014

18. H. Ravaee, F. Saeid, S. Faramarz, Artificial neural network based model of photovoltaic thermal $(\mathrm{PV} / \mathrm{T})$ collector, J. Math. Comput. Sci. 4, 411 (2012)

19. R. Karthikeyan, A.K. Parvathy, Study of $\mathrm{Pv}$ panels and analysis of various Mppt techniques, J. Theor. Appl. Inf. Technol. 68, 463 (2014)

20. P. Shaw1, Modelling and analysis of an analogue PPT based PV battery charging system utilizing dc-dc boost converter, IET Renew. Power Gener. 13, 1958 (2019)

21. S. Chowdhury, Design \& estimation of rooftop grid-tied solar photovoltaic system, Thesis, 2016

22. G. El-Saady, A. El-NobiIbrahim, M. EL-Hendawi, Simulated annealing modeling and analog MPPT simulation for standalone photovoltaic arrays, Int. J. Power Eng. Energy 4, $353(2013)$

23. J.M. Enrique, J.M. Andujar, M.A. Bohoérquez, A reliable, fast and low cost maximum power point tracker for photovoltaic applications, Solar Energy 84, 79 (2010)

24. http://www.labcenter.com/index.cfm

25. N. Mhiri, A. Alahdal, H. Ghulman, A. Ammous, Design of a new analog circuit for maximum power point tracking of photovoltaic panels, in 7th International Renewable Energy Congress IREC'2016 (2016)

26. N. Mhiri, A Alahdal, H. Ghulman, A. Ammous, A novel analog circuit design for maximum power point tracking of photovoltaic panels, Hindawi Adv. Power Electr. 2017, 9409801 (2017)

27. A Alahdal, N. Mhiri, H. Ghulman, A. Ammous, Realization of a new analog circuit for maximum power point tracking of photovoltaic panels, Int. J. Appl. Eng. Res. 13, 2412 (2018)

28. C.-Y. Hsieh, C.-Y. Yang, F.-K. Feng, K.-H. Chen, A photovoltaic system with an analog maximum power point tracking technique for $97.3 \%$ high effectiveness, in 2010 Proceedings of ESSCIRC (IEEE, 2010)

29. Z. Liang, R. Guo, A. Huang, A new cost-effective analog maximum power point tracker for PV systems, in 2010 IEEE Energy Conversion Congress and Exposition (IEEE, 2010)

30. A. Aziz, K. Kassmi, M. Hamdaoui, F. Olivie, Design and modelling of a photovoltaic system optimized by an analog control provided with a detection circuit of dysfunction and restarting of the system, in 2007 International Conference on Design $\&$ Technology of Integrated Systems in Nanoscale Era (IEEE, 2007)

31. Y. Wang, Analog maximum power point tracking (MPPT) IC for solar cells, Thesis, USA, 2014

32. M. El Ouariachi, T. Mrabti, B. Tidhaf, Ka. Kassmi, K. Kassmi, Regulation of the electric power provided by the panels of the photovoltaic systems, Int. J. Phys. Sci. 4, 294 (2009) 
33. Tutorial Cadence Virtuoso, Virtuoso - Les premiers pas JMG / LL / PN - 2015, http://www.lirmm.fr/ nouet/homepage/pdf_files/Cadence\%20Polytech\% 202015.pdf

34. P.E. Allen, D.R. Holberg, CMOS Analog Circuit Design (Oxford University Press, New York, 2002)
35. G. Venkatrao, B. Mamatha, B. Jugal Kishore, Design of low power and high CMRR two stage CMOS operational amplifier in 180nm technology, Int. J. Innov. Res. Sci. 5 (2016)

36. N.V. Divyashree, U. Desai, A. Kiran, Design of two-stage CMOS operational amplifier suitable for signal conditioning, Int. J. Innov. Res. Sci. Eng. Technol. 5, 6746 (2016)

Cite this article as: Abdulrahman Alahdal, Anis Ammous, Kaiçar Ammous, Design and realization of an analog integrated circuit for maximum power point tracking of photovoltaic panels, EPJ Photovoltaics 13, 6 (2022) 